\title{
The Ethical, Legal, and Social Issues Impacted by Modern Assisted Reproductive Technologies
}

\author{
Paul R. Brezina and Yulian Zhao \\ Division of Reproductive Endocrinology and Infertility, Department of Gynecology and Obstetrics, \\ Johns Hopkins Medical Institutions, Phipps 264600 N. Wolfe Street, Baltimore, MD 21287, USA \\ Correspondence should be addressed to Paul R. Brezina, pbrezin1@jhmi.edu
}

Received 21 July 2011; Accepted 25 November 2011

Academic Editor: B. S. Garg

Copyright (๑) 2012 P. R. Brezina and Y. Zhao. This is an open access article distributed under the Creative Commons Attribution License, which permits unrestricted use, distribution, and reproduction in any medium, provided the original work is properly cited.

Background. While assisted reproductive technology (ART), including in vitro fertilization has given hope to millions of couples suffering from infertility, it has also introduced countless ethical, legal, and social challenges. The objective of this paper is to identify the aspects of ART that are most relevant to present-day society and discuss the multiple ethical, legal, and social challenges inherent to this technology. Scope of Review. This paper evaluates some of the most visible and challenging topics in the field of ART and outlines the ethical, legal, and social challenges they introduce. Major Conclusions. ART has resulted in a tectonic shift in the way physicians and the general population perceive infertility and ethics. In the coming years, advancing technology is likely to exacerbate ethical, legal, and social concerns associated with ART. ART is directly challenging society to reevaluate the way in which human life, social justice and equality, and claims to genetic offspring are viewed. Furthermore, these issues will force legal systems to modify existing laws to accommodate the unique challenges created by ART. Society has a responsibility to ensure that the advances achieved through ART are implemented in a socially responsible manner.

\section{Introduction}

ART is currently a commonplace technology that has successfully treated millions of infertile couples the world over. However, the explosion of this technology has introduced a myriad of new social, ethical, and legal challenges. This paper evaluates some of the most visible and challenging topics in the field of ART and outlines the ethical, legal and social challenges they introduce.

\section{Scope of ART Utilization}

Infertility has traditionally been an area of medicine in which physicians had limited means to help their patients. The landscape of this field changed dramatically with the announcement of the birth of Louise Brown in 1978 through in vitro fertilization (IVF). This historic moment was eloquently encapsulated by Howard Jones who observed "Eleven forty-seven p.m. Tuesday, July 25, 1978, was surely a unique moment in the life of Patrick Steptoe. This was the hour and minute he delivered Louise Brown, the world's first baby, meticulously, lovingly, and aseptically conceived in the laboratory, but popularly referred to as the world's first test tube baby" [1]. The importance of this birth to scientists, clinicians, and most particularly infertile patients throughout the world cannot be overstated. In several short decades, IVF has exploded in availability and use throughout the world.

Worldwide, more than 70 million couples are afflicted with infertility [2]. Since the first successful IVF procedure in 1978 [3], the use of this and related technologies has expanded to become commonplace around the globe. Over the past decade, the use of ART services has increased at a rate of 5-10\% annually $[4,5]$.

In 1996, approximately 60,000 IVF cycles were initiated in the United States with approximately 17,000 clinical pregnancies and 14,000 live births [6]. Currently, IVF accounts for approximately $1 \%$ of all live births in the United States [6]. As of 2009, 3.4 million children have been born worldwide after ART treatment, and ART utilization is 
currently increasing at a rate of 5-10\% annually in developed countries [4].

\section{Reporting Regulations}

The widespread use of this technology throughout the world has prompted a desire by the public, governmental bodies, and professional organizations to create mechanisms that evaluate the utilization of ART. Advances in the arena of assisted reproductive technologies (ART) are accompanied by ethical and societal concerns. Legislation and professional societies have attempted to address these concerns for some time. For example, in 1986, the American Fertility Society first published guidelines for the ethical implementation of ART in the United States [7]. The dynamic nature of ART and the rapid evolution of the field result in constant paradigm shifts that require frequent and comprehensive evaluation by professional organizations and society alike.

In the 1980's, concerns surrounding ART focused on the safe administration of gonadotropins, transparency of pregnancy data from clinics, and addressing economic barriers to ART access. Some of these issues, such as reporting requirements for ART pregnancy results, have also been mandated with legislation in many nations [8]. Furthermore, ART reporting requirements generally include the number of embryos transferred. This measure has been extremely important in correlating the risk of multiple gestations with the transfer of 2 or more embryos. However, in many nations, reporting regulations are not accompanied by legislation defining practice patterns. For example, in the United States, while physicians are required to report the number of embryos transferred in an IVF cycle, there are no laws that state the allowed number of embryos transferred [8].

Through centralized mandatory reporting registries, general estimates of IVF activity are available in many nations. In an effort to define current IVF statistics and to make this information more transparent and available to patients, the Fertility Clinic Success Rate and Certification Act of 1992 was created in the United States [8]. This law requires clinics providing IVF in the United States to report specific information regarding IVF cycles, including pregnancy rates [6]. This reporting data is only reported on IVF cycle outcomes and does not include detailed information regarding the maternal or paternal medical history [6]. In other countries, similar national registries exist [5], making it possible to evaluate data from IVF cycles on both a national and international scale. A detailed accounting for ART reporting and regulations across the globe is available from the International Federation of Fertility Societies (IFFS) [5]. In their 2010 report, the IFFS reported ART outcomes data from 59 countries [5].

Such laws were implemented in an attempt to ensure that patients may be informed as to which clinics have superior ART pregnancy results. In some instances, however, this has led to some clinics "cherry picking" patients to improve their overall pregnancy results. This has actually become a barrier to receiving ART for many patients with a relatively poor pregnancy prognosis.

\section{Practice Regulations and Multiple Gestation Pregnancies}

Federally mandated regulations, however, are not limited to registries. Increasingly, nations have enacted legislation that defines the parameters for acceptable practice of ART. The transfer of multiple embryos in a single cycle increases the rates of multiple births [9]. Because of the increased social costs and health risks associated with multiple births, legislation or guidelines from professional societies have been introduced in many countries restricting the number of embryos that may be transferred per IVF cycle in an effort to limit the incidence of multiple gestations [9-11]. Indeed, a study in the United Kingdom found that the total health

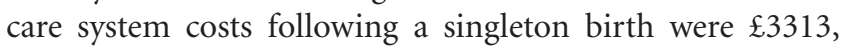

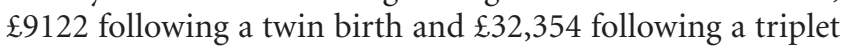
birth [9]. Additionally, the health risks, both to the mother and the infant, increase dramatically with increasing number of infants [9]. In the United States in 2007, the number of embryos transferred per cycle ranged from 2.2 in women under 35 to 3.1 in women over 40 years of age (CDC). Multiple birth rates in the United States in 2007 ranged from approximately $35 \%$ in women under 35 to $15 \%$ in women over the age of 40 [12]. In Europe, the approximate number of embryos transferred in the year 2006 was one (22\%), two (57\%), three (19\%), or four (1.6\%) [13]. In $2007,79.2 \%$ of European births were singletons, with a twin rate of $19.9 \%$ and a triplet rate of $0.9 \%$ [5].

Pregnancy rates associated with IVF are high compared to those seen in the early days of the procedure. The current efficiency of IVF is more cost effective and efficacious in achieving pregnancy than other modalities, such as injectable gonadotropins coupled with intra uterine insemination (IUI), which traditionally some have preferred [14]. The increased efficiency of IVF has also resulted in an increased rate of multiple gestations. Recent data suggests that single embryo transfer, coupled with subsequent frozen embryo transfer, results in equivalent pregnancy rates compared with the transfer of multiple embryos, without an increase in multiple pregnancy rates [11]. Additionally, single embryo transfer would inherently decrease maternal and infant health risks associated with multiple gestation pregnancies [9]. Therefore, a trend toward single embryo transfer is likely to increase in the future.

Variability of legislation regulating IVF exists in different countries and even states/provinces within a single nation [6]. For example, in an effort to minimize multiple gestation pregnancies resulting from ART, some laws place limits on the number of embryos that may be transferred, cryopreserved, or fertilized per IVF cycle $[5,6,15,16]$. In some cases, these regulations or fiscal pressures result in couples traveling across international border to obtain treatments that are unavailable in their native country [17]. This practice, known as cross-border reproductive care (CBRC), is thought to account for as much as $10 \%$ of the total IVF cycles performed worldwide $[17,18]$. 


\section{Financial Aspect for IVF Treatment}

Perhaps one of the most obvious ethical challenges surrounding ART is the inequitable distribution of access to care. The fact that significant economic barriers to IVF exist in many countries results in the preferential availability of these technologies to couples in a position of financial strength [19]. The cost of performing ART per live birth varies among countries [4]. The average cost per IVF cycle in the United States is USD 9,266 [20]. However, the cost per live birth for autologous ART treatment cycles in the United States, Canada, and the United Kingdom ranged from approximately USD 33,000 to 41,000 compared to USD 24,000 to 25,000 in Scandinavia, Japan, and Australia [14]. The total ART treatment costs as a percentage of total healthcare expenditures in 2003 were $0.06 \%$ in the United States, $0.09 \%$ in Japan, and $0.25 \%$ in Australia [4]. Some have maintained that the cost for these cycles pales in comparison to the social advantages yielded by the addition of productive members of society [21]. This is especially true in societies that have a negative or flat population growth rate coupled with an aging population [21].

The funding structure for IVF/ART is highly variable among different nations. For example, no federal government reimbursement exists for IVF in the United States, although certain states have insurance mandates for ART [4, $19,22]$. Many other countries provide full or partial coverage through governmental insurance $[4,9]$. In many instances, long waiting times for IVF through these government programs encourage couples to seek treatment in private fertility centers that accept remuneration directly from the patients $[4,23,24]$. In the United Kingdom, for example, only approximately $25 \%$ of all IVF cycles performed are funded by the National Health Service [9].

\section{Preimplantation Genetic Testing}

Preimplantation genetic screening (PGS) and diagnosis (PGD) offer the unique ability to characterize the genetic composition of embryos prior to embryo transfer. Given the recent successes of these technologies, the broader implementation of this technology in the future is likely. Although controversial, using PGD to choose embryos solely on the basis of gender is currently being practiced $[25,26]$. Sex selection in the proper setting may offer a substantial health benefit. For example, choosing to transfer only embryos of a certain sex may confer a therapeutic benefit if used to avoid a known sex linked disorder. However, sex selection PGD purely for the preference of the parents could conceivably, if practiced on a large scale, skew the gender proportions in certain nations where one gender is culturally preferred.

In the near future, with refinements in microarray technology and the defining of genetic sequences associated with certain physical characteristics, it is conceivable that specific physical or mental characteristics may be evaluated to guide the decision as to which embryos to transfer. This possibility raises concerns on both ethical and practical levels. Of more concern is the possibility that in the future, technology will permit the manipulation of genetic material within an embryo. Rigorous public and scientific oversight of these technologies is vital to ensure that scientific advances are tempered with the best interests of society in mind.

\section{Fertility Preservation}

Female fertility is well documented to decrease with age $[27,28]$. Consequently, much research has been conducted aimed at preserving female fertility before advanced age is realized. Additionally, fertility preservation for individuals afflicted with cancer has important implications as often the chemotherapeutic agents used to treat cancer are toxic to the ovary and result in diminished ovarian reserve and reduced fertility. While techniques for freezing sperm and embryos are well established, techniques for freezing oocytes and ovarian tissue are still considered experimental [29]. Multiple techniques including oocyte cryopreservation and preservation of strips of ovarian cortex with subsequent reimplantation and stimulation have been described, with some pregnancy success [30-33]. Fertility preservation for cancer patients using in vitro maturation (IVM), oocyte vitrification and the freezing of intact human ovaries with their vascular pedicles have also been reported [34]. As of 2008, more than 5 babies had been delivered through IVF following ovarian tissue transplantation [35]. Many have suggested that, prior to being treated for cancer, women should be offered fertility preservation measures as outlined above [34].

Recently, several laboratories have demonstrated the ability to successfully cryopreserve oocytes following an IVF cycle. These developments have profound implications. As the birth control pill gave women the ability to prevent pregnancy, oocyte cryopreservation may give women the flexibility to preserve their fertility potential, starting at a young age, while postponing childbearing. However, as this technology at the present time in many countries is generally only available to those with financial means. This poses ethical and social issues that will certainly see more attention in the future.

\section{Gamete Donation}

The use of donor gametes, either in the form of donor sperm or donor oocytes, is commonplace in ART. The use of donor sperm can be traced to the 1800's [36]. In the mid 1980s, oocyte donation was introduced [36]. In recent years, issues surrounding the use of donor gametes have become increasingly visible [37]. Women donating oocytes must undergo IVF. Due to the inherent medical risks associated with IVF, including ovarian hyperstimulation syndrome and surgical risks, a central concern of allowing women to be oocyte donors includes adequate informed consent [37]. Consent, in addition to outlining these medical risks, should include counseling regarding the emotional benefits and risks of donation with an emphasis that long-term data regarding these risks are lacking [37]. Additionally, it is considered an ethical prerequisite that oocyte donors participate voluntarily and without coercion or undue influence [38]. Some have 
expressed concern that financial compensation of oocyte donors may lead to exploitation as women may proceed with oocyte donation against their own best interests, given the inherent medical risks involved [39]. The concept of commodification, that any "buying or selling" of human gametes is inherently immoral, is an additional argument used against remunerating women serving as oocyte donors [39]. Due to the substantial controversy surrounding oocyte donation, especially the amount of financial compensation may be given to an oocyte donor, federal regulations governing this practice are constantly evolving and differ substantially from country to country [39].

Another ethical and legal issue surrounding the use of donated gametes is to what extent the anonymity of the donor should be preserved. The issue of anonymity as it relates to gamete and embryo donation is emotionally charged. Indeed, the ability of human beings to know their genetic roots is universally important, at the core of self identity. Either egg and sperm donors may choose to or not to be anonymous, though the vast majority in both groups generally chooses anonymity [40]. The American Society for Reproductive Medicine has identified four levels of gamete donor information sharing depending on the wishes of the donor and recipient parties [37]. Recently, however, there is, increasing consideration of the rights of offspring as it relates to donor gametes and anonymity [40]. Advocates for allowing either gamete donors or their offspring to break anonymity cite the medical advantages of sharing medical information with their genetic offspring, in the case of the donor, or learning about their genetic history directly, in the case of offspring [41, 42]. Others simply argue that both donors and offspring have an inherent right to meet and develop a relationship [43]. Recent court rulings suggest that these rights will become more visible in the future. For example, in the British case Rose $v$ Secretary of State for Health [2002] EWHC 1593, the court ruled that based on the Human Rights Act, donor offspring could obtain information about their genetic parents despite previously established anonymity [43]. The ethical and legal issues surrounding anonymity and gamete donation are sure to be a centrally debated issues within the field of ART for the foreseeable future.

\section{Embryo Donation}

IVF cycles often result in couples transferring several embryos and cryopreserving other embryos produced by the cycle, presumptively for the purpose future pregnancy. However, in many instances, these surplus embryos are never used by the genetic parents and therefore are stored indefinitely [44]. The number of such embryos stored internationally is surprisingly high. In the United States alone, it is estimated that over 400,000 embryos are currently cryopreserved, many of which will not be used by their genetic parents [44]. The ethical and moral issues surrounding how to deal with these surplus embryos have been the source of much debate. In general, four possible fates for these embryos exist [44]:
(1) thawing and discarding,

(2) donating to research,

(3) indefinite storage,

(4) donating the embryos to another couple for the purposes of uterine transfer.

All of these strategies have staunch supporters and detractors. Not surprisingly, there are a myriad of laws in different countries governing many aspects of how a human embryo that has been cryopreserved may be handled $[44,45]$. The use of embryos for the purpose of research, specifically as it relates to human stem cells, has also been a source of fierce debate internationally and has resulted in substantial regulation that varies substantially from nation to nation [46-49].

\section{Surrogacy and Gestational Carriers}

Another topic of ethical, social, and legal debate surrounds the use of surrogacy and gestational carriers. Surrogacy is defined as a woman who agrees to carry a pregnancy using her own oocytes but the sperm of another couple and relinquish the child to this couple upon delivery [50]. A gestational carrier, by contrast, involves a couple who undergoes IVF with their genetic gametes and then places the resultant embryo in another woman's uterus, the gestational carrier, who will carry the pregnancy and relinquish the child to this couple upon delivery [50]. Currently, the use of gestational carriers is far more common than that of surrogates [50].

As with donor gametes, surrogates and gestational carriers are subject to significant medical and emotional risks from carrying a pregnancy and undergoing a delivery [50]. As such, extensive counseling and meticulous informed consent are required [50]. Some also are concerned that the use of surrogates and gestational carriers is a form of "child selling" or the "sale of parental rights" [51]. Additionally, the rights of the surrogate or gestational carrier to not relinquish the infant following deliver are not well described [50]. In fact, legal precedent in some states within the United States has actually upheld the right of a birth mother, regardless of genetic relation to the child, to retain parental rights despite the existence of a preexisting gestational carrier contract [50].

Another central concern surrounding the use of surrogates and gestational carriers is the possibility that financial pressures could lead to exploitation and commoidification of the service [50-53]. The mean compensation for a gestational carrier in the United State in 2008 was estimated at approximately $\$ 20,000$ [50]. In contrast, a gestational carrier in India receives an average of $\$ 4,000$ for the same service [52]. Regulation of surrogates and gestational carriers varies widely from nation to nation and even within regions of individual countries $[50,52-56]$. Due to these financial and legal considerations, international surrogacy has emerged as an emerging industry, especially in developing nations [52]. This practice has exacerbated the already difficult ethical and legal issues surrounding gestational carriers [52]. At the present time, issues surrounding issues of individual rights, commoidification, exploitation, citizenship of the offspring 
of international gestational carriers, and even fair trade are largely unresolved internationally $[52,55]$.

\section{Possible Deleterious Effects of ART}

There are questions that remain outstanding regarding the use of IVF. Conflicting data exists about the risks of IVF on the developing embryo. Multiple studies have failed to find a clinically relevant association between IVF or embryo cryopreservation and adverse maternal or fetal effects [5759]. Other studies have suggested that infants of IVF pregnancies may be at a small but statistically significant increased risk for rare epigenetic and other abnormalities [6062].

Despite this controversy, there is a general consensus that IVF confers a small but measurable increased risk for a variety of congenital abnormalities including anatomic abnormalities and imprinting errors as compared to the general population [63]. Some maintain, however, that this is secondary to an increased baseline risk for these problems in the population of infertile patients [63]. Regardless of the cause, this small increased risk, while statistically significant with extremely large sample sizes, will likely not be a powerful enough factor to dissuade infertile couples from pursuing parenthood through IVF.

\section{Conclusion}

ART has emerged as one of the most widely adopted and successful medical technologies in the last century. While giving hope to millions of couples suffering from infertility, ART also has presented new ethical, legal, and social questions that society must address. Many countries have taken steps to regulate certain aspects of ART. Specifically, what regulations and laws should be in place for ART reporting, social inequities that may arise from financial barriers to ART, genetic testing, emerging laboratory techniques that have improved embryo and gamete survival when cryopreserved, and an individual's right to their genetic offspring in the setting of gamete or embryo donation are aspects of ART which will become increasingly controversial and debated into the future.

However, the lion's share of ethical and legal questions that exist surrounding ART have yet to be resolved. Society must reconcile how to fund ART in a responsible and equitable manner to increase access to care. Additionally, the myriad of unresolved issues surrounding gamete and embryo donation must be addressed in greater detail in future social and legal dialogues.

ART is a field that is dynamic and ever changing. In areas of ART such as preimplantation genetics, new technologies continually change the capabilities of ART. Due to the rapidly evolving nature of the ART, legislation is often unable to keep pace and address all of the ethical and legal issues that are constantly emerging in the field. It is therefore incumbent upon physicians to continually monitor these issues and ensure that ART technologies are offered and delivered in a manner that balances patient care with social and moral responsibility.

\section{Conflict of Interests}

The authors declare that there is no conflict of interests.

\section{References}

[1] H. W. Jones, "Moments in the life of Patrick Steptoe," Fertility and Sterility, vol. 66, no. 1, pp. 15-16, 1996.

[2] W. Ombelet, I. Cooke, S. Dyer, G. Serour, and P. Devroey, "Infertility and the provision of infertility medical services in developing countries," Human Reproduction Update, vol. 14, no. 6, pp. 605-621, 2008.

[3] P. C. Steptoe and R. G. Edwards, "Birth after the reimplantation of a human embryo," The Lancet, vol. 2, no. 8085, p. 366, 1978.

[4] G. M. Chambers, E. A. Sullivan, O. Ishihara, M. G. Chapman, and G. D. Adamson, "The economic impact of assisted reproductive technology: a review of selected developed countries," Fertility and Sterility, vol. 91, no. 6, pp. 2281-2294, 2009.

[5] H. W. Jones, I. Cooke, R. Kempers, P. Brinsden, and D. Saunders, "International federation of fertility societies surveillance," Fertility and Sterility, vol. 95, no. 2, p. 491, 2011.

[6] L. A. Schieve, H. B. Peterson, S. F. Meikle et al., "Livebirth rates and multiple-birth risk using in vitro fertilization," Journal of the American Medical Association, vol. 282, no. 19, pp. 1832-1838, 1999.

[7] American Fertility Society and Ethics Committee, "Ethical considerations of the new reproductive technologies," Fertility and Sterility, vol. 46, no. 3, supplement 1, pp. 1S-94S, 1986.

[8] "Fertility Clinic Success Rate and Certification Act of 1992 (FCSRCA)," Pub. L. no.102 —493,1992.

[9] W. L. Ledger, D. Anumba, N. Marlow, C. M. Thomas, and E. C. Wilson, "The costs to the NHS of multiple births after IVF treatment in the UK," Journal of Obstetrics and Gynaecology, vol. 113, no. 1, pp. 21-25, 2006.

[10] ASRM Practice Committee, "Guidelines on number of embryos transferred," Fertility and Sterility, vol. 92, no. 5, pp. 15181519, 2009.

[11] D. J. McLernon, K. Harrild, C. Bergh et al., "Clinical effectiveness of elective single versus double embryo transfer: metaanalysis of individual patient data from randomised trials," BMJ, vol. 341, Article ID c6945, 2010.

[12] http://www.cdc.gov/art/.

[13] A. Massip, P. Mermillod, and A. Dinnyes, "Morphology and biochemistry of in-vitro produced bovine embryos: implications for their cryopreservation," Human Reproduction, vol. 10, no. 11, pp. 3004-3011, 1995.

[14] R. H. Reindollar, M. M. Regan, P. J. Neumann et al., "A randomized clinical trial to evaluate optimal treatment for unexplained infertility: the fast track and standard treatment (FASTT) trial," Fertility and Sterility, vol. 94, no. 3, pp. 888899, 2010.

[15] P. E. L. Setti, E. Albani, A. Cesana et al., "Italian constitutional court modifications of a restrictive assisted reproduction technology law significantly improve pregnancy rate," Human Reproduction, vol. 26, no. 2, pp. 376-381, 2011.

[16] E. G. Hughes and D. DeJean, "Cross-border fertility services in North America: a survey of Canadian and American providers," Fertility and Sterility, vol. 94, no. 1, pp. e16-e19, 2010. 
[17] J. Collins and J. Cook, "Cross-border reproductive care: now and into the future," Fertility and Sterility, vol. 94, no. 1, pp. e25-e26, 2010.

[18] A. P. Ferraretti, G. Pennings, L. Gianaroli, F. Natali, and M. C. Magli, "Cross-border reproductive care: a phenomenon expressing the controversial aspects of reproductive technologies," Reproductive BioMedicine, vol. 20, no. 2, pp. 261-266, 2010.

[19] T. Jain and M. D. Hornstein, "Disparities in access to infertility services in a state with mandated insurance coverage," Fertility and Sterility, vol. 84, no. 1, pp. 221-223, 2005.

[20] K. R. Omurtag, A. K. Styer, D. Session, and T. L. Toth, "Economic implications of insurance coverage for in vitro fertilization in the United States: a review," The Journal of Reproductive Medicine, vol. 54, no. 11-12, pp. 661-668, 2009.

[21] J. Garcia, "Profiling assisted reproductive technology: the society for assisted reproductive technology registry and the rising costs of assisted reproductive technology," Fertility and Sterility, vol. 69, no. 4, pp. 624-626, 1998.

[22] P. Mladovsky and C. Sorenson, "Public financing of IVF: a review of policy rationales," Health Care Analysis, vol. 18, no. 2, pp. 113-128, 2010.

[23] R. Klemetti, M. Gissler, and E. Hemminki, "Equity in the use of IVF in Finland in the late 1990s," Scandinavian Journal of Public Health, vol. 32, no. 3, pp. 203-209, 2004.

[24] World Health Organization, "Infections, pregnancies, and infertility: perspectives on prevention," Fertility and Sterility, vol. 47, no. 6, pp. 964-968, 1987.

[25] R. R. Sharp, M. L. McGowan, J. A. Verma et al., "Moral attitudes and beliefs among couples pursuing PGD for sex selection," Reproductive BioMedicine, vol. 21, no. 7, pp. 838-847, 2010.

[26] K. Ehrich, C. Williams, B. Farsides, J. Sandall, and R. Scott, "Choosing embryos: ethical complexity and relational autonomy in staff accounts of PGD," Sociology of Health and Illness, vol. 29, no. 7, pp. 1091-1106, 2007.

[27] I. A. van Rooij, L. F. Bancsi, F. J. Broekmans, C. W. Looman, J. D. Habbema, and E. R. Te Velde, "Women older than 40 years of age and those with elevated follicle-stimulating hormone levels differ in poor response rate and embryo quality in in vitro fertilization," Fertility and Sterility, vol. 79, no. 3, pp. 482488, 2003.

[28] S. D. Spandorfer, K. Bendikson, K. Dragisic, G. Schattman, O. K. Davis, and Z. Rosenwaks, "Outcome of in vitro fertilization in women 45 years and older who use autologous oocytes," Fertility and Sterility, vol. 87, no. 1, pp. 74-76, 2007.

[29] ASRM Ethics Committee Report, "Fertility preservation and reproduction in cancer patients," Fertility and Sterility, vol. 83, no. 6, pp. 1622-1628, 2005.

[30] E. Porcu, R. Fabbri, G. Damiano, R. Fratto, S. Giunchi, and S. Venturoli, "Oocyte cryopreservation in oncological patients," European Journal of Obstetrics Gynecology and Reproductive Biology, vol. 113, supplement 1, pp. S14-S16, 2004.

[31] N. Noyes, J. Boldt, and Z. P. Nagy, "Oocyte cryopreservation: is it time to remove its experimental label?" Journal of Assisted Reproduction and Genetics, vol. 27, no. 2-3, pp. 69-74, 2010.

[32] J. Donnez, J. Squifflet, P. Jadoul et al., "Pregnancy and live birth after autotransplantation of frozen-thawed ovarian tissue in a patient with metastatic disease undergoing chemotherapy and hematopoietic stem cell transplantation," Fertility and Sterility, vol. 95, no. 5, pp. 1787.e1-1787.e4, 2011.

[33] E. Ernst, S. Bergholdt, J. S. Jørgensen, and C. Y. Andersen, "The first woman to give birth to two children following transplantation of frozen/thawed ovarian tissue," Human Reproduction, vol. 25, no. 5, pp. 1280-1281, 2010.

[34] G. D. Rao, R. C. Chian, W. S. Son et al., "Fertility preservation in women undergoing cancer treatment," The Lancet, vol. 363, no. 9423, pp. 1829-1830, 2004.

[35] D. Meirow, "Fertility preservation in cancer patients using stored ovarian tissue: clinical aspects," Current Opinion in Endocrinology, Diabetes and Obesity, vol. 15, no. 6, pp. 536$547,2008$.

[36] T. F. Murphy, "Ethics and the prohibition of donor gametes in fertility medicine," Reproductive BioMedicine, vol. 18, supplement 1, pp. 60-67, 2009.

[37] Ethics Committee of the American Society for Reproductive Medicine, "Interests, obligations, and rights of the donor in gamete donation," Fertility and Sterility, vol. 91, no. 1, pp. 2227, 2009.

[38] E. D. Levens and A. H. DeCherney, "Human oocyte research: the ethics of donation and donor protection," Journal of the American Medical Association, vol. 300, no. 18, pp. 2174-2176, 2008.

[39] A. D. Levine, "The oversight and practice of oocyte donation in the United States, United Kingdom and Canada," HEC Forum, vol. 23, no. 1, pp. 15-30, 2011.

[40] J. L. Sauer, "Competing interests and gamete donation: the case for anonymity," Seton Hall Law Review, vol. 39, no. 3, pp. 919-954, 2009.

[41] V. Jadva, T. Freeman, W. Kramer, and S. Golombok, "Sperm and oocyte donors experiences of anonymous donation and subsequent contact with their donor offspring," Human Reproduction, vol. 26, no. 3, pp. 638-645, 2011.

[42] D. W. Riggs and L. Russell, "Characteristics of men willing to act as sperm donors in the context of identity-release legislation," Human Reproduction, vol. 26, no. 1, pp. 266-272, 2011.

[43] J. A. Burr, "To name or not to name? An overview of the social and ethical issues raised by removing anonymity from sperm donors," Asian Journal of Andrology, vol. 12, no. 6, pp. 801806, 2010.

[44] M. S. Paul, R. Berger, E. Blyth, and L. Frith, "Relinquishing frozen embryos for conception by infertile couples," Families, Systems and Health, vol. 28, no. 3, pp. 258-273, 2010.

[45] Ethics Committee of the American Society for Reproductive Medicine, "American society for reproductive medicine: defining embryo donation," Fertility and Sterility, vol. 92, no. 6, pp. 1818-1819, 2009.

[46] K. Hug, "Motivation to donate or not donate surplus embryos for stem-cell research: literature review," Fertility and Sterility, vol. 89, no. 2, pp. 263-277, 2008.

[47] T. Kalista, H. A. Freeman, B. Behr, R. R. Pera, and C. T. Scott, "Donation of embryos for human development and stem cell research," Cell Stem Cell, vol. 8, no. 4, pp. 360-362, 2011.

[48] F. Baylis, "For love or money? The saga of Korean women who provided eggs for embryonic stem cell research," Theoretical Medicine and Bioethics, vol. 30, no. 5, pp. 385-396, 2009.

[49] S. L. Crockin, "A legal defense for compensating research egg donors," Cell Stem Cell, vol. 6, no. 2, pp. 99-102, 2010.

[50] S. James, R. Chilvers, D. Havemann, and J. Y. Phelps, "Avoiding legal pitfalls in surrogacy arrangements," Reproductive BioMedicine, vol. 21, no. 7, pp. 862-867, 2010.

[51] J. K. Hanna, "Revisiting child-based objections to commercial surrogacy," Bioethics, vol. 24, no. 7, pp. 341-347, 2010.

[52] C. Humbyrd, "Fair trade international surrogacy," Developing World Bioethics, vol. 9, no. 3, pp. 111-118, 2009. 
[53] N. Gamble, "Crossing the line: the legal and ethical problems of foreign surrogacy," Reproductive BioMedicine, vol. 19, no. 2, pp. 151-152, 2009.

[54] B. Osberg, "For your first born child: an ethical defense of the exploitation argument against commercial surrogacy," Penn Bioethics Journal, vol. 2, no. 2, pp. 42-45, 2006.

[55] J. Damelio and K. Sorensen, "Enhancing autonomy in paid surrogacy," Bioethics, vol. 22, no. 5, pp. 269-277, 2008.

[56] K. Drabiak, C. Wegner, V. Fredland, and P. R. Helft, "Ethics, law, and commercial surrogacy: a call for uniformity," Journal of Law, Medicine and Ethics, vol. 35, no. 2, pp. 300-309, 2007.

[57] U. B. Wennerholm, V. Söderström-Anttila, C. Bergh et al., "Children born after cryopreservation of embryos or oocytes: a systematic review of outcome data," Human Reproduction, vol. 24, no. 9, pp. 2158-2172, 2009.

[58] H. Logerot-Lebrun, J. De Mouzon, A. Hachelot, and A. Spira, "Pregnancies and births resulting from in vitro fertilization: French national registry, analysis of data 1986 to 1990, FIVNAT (French In Vitro National)," Fertility and Sterility, vol. 64, no. 4, pp. 746-756, 1995.

[59] K. Petersen, P. J. Hornnes, S. Ellingsen et al., "Perinatal outcome after in vitro fertilisation," Acta Obstetricia et Gynecologica Scandinavica, vol. 74, no. 2, pp. 129-131, 1995.

[60] M. Ceelen, M. M. van Weissenbruch, J. P. W. Vermeiden, F. E. van Leeuwen, and H. A. Delemarre-van de Waal, "Growth and development of children born after in vitro fertilization," Fertility and Sterility, vol. 90, no. 5, pp. 1662-1673, 2008.

[61] E. L. Niemitz and A. P. Feinberg, "Epigenetics and assisted reproductive technology: a call for investigation," American Journal of Human Genetics, vol. 74, no. 4, pp. 599-609, 2004.

[62] L. N. Odom and J. Segars, "Imprinting disorders and assisted reproductive technology," Current Opinion in Endocrinology, Diabetes and Obesity, vol. 17, no. 6, pp. 517-522, 2010.

[63] A. Fortunato and E. Tosti, "The impact of in vitro fertilization on health of the children: an update," European Journal of Obstetrics Gynecology and Reproductive Biology, vol. 154, no. 2, pp. 125-129, 2011. 


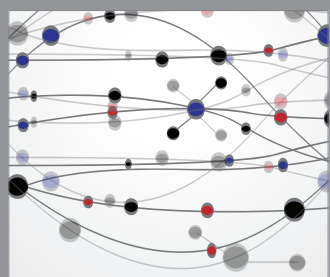

The Scientific World Journal
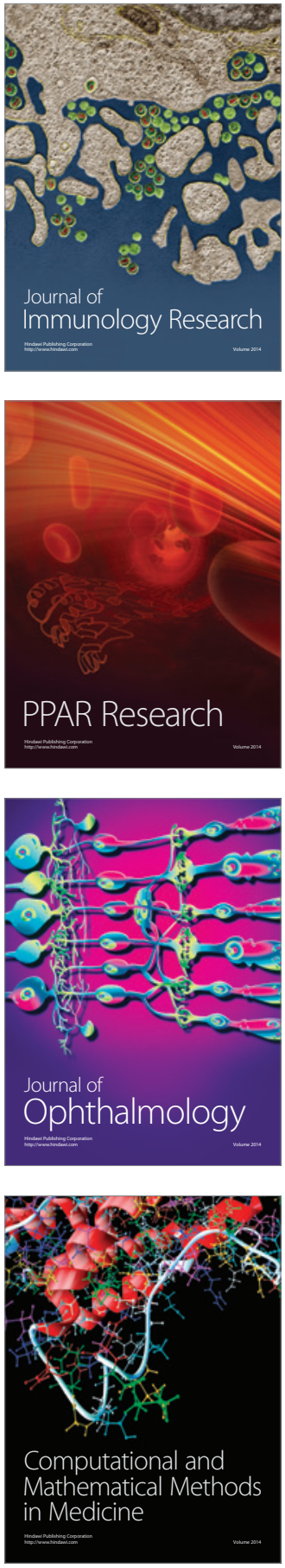

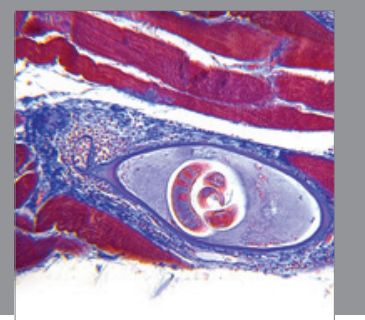

Gastroenterology

Research and Practice
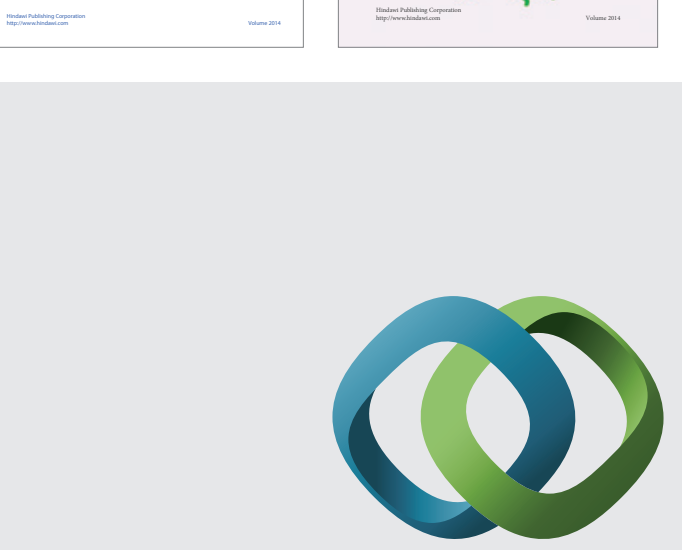

\section{Hindawi}

Submit your manuscripts at

http://www.hindawi.com
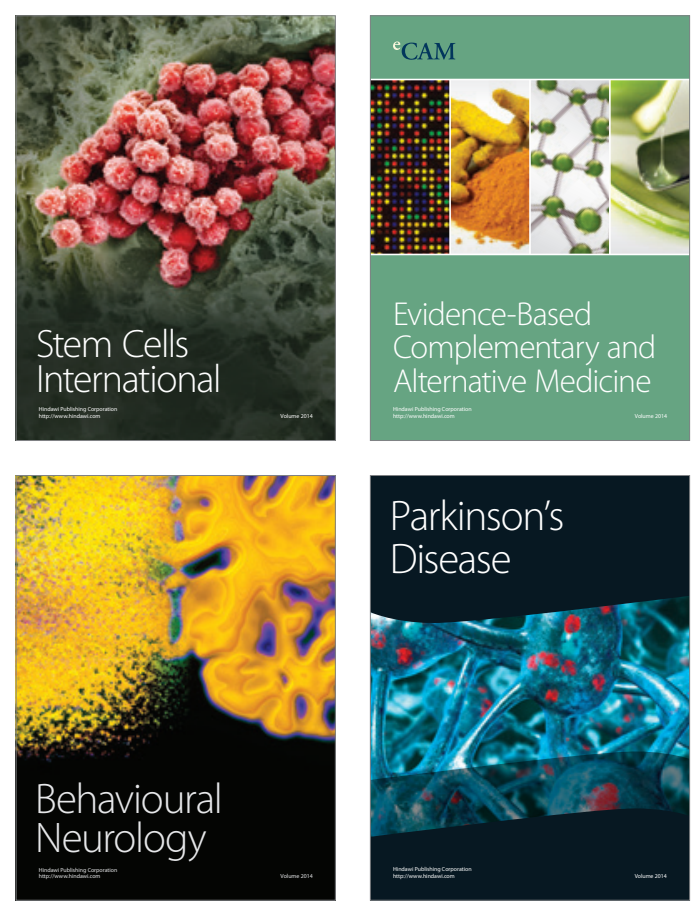

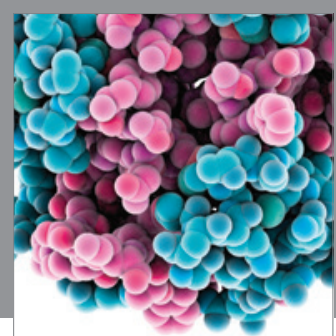

Journal of
Diabetes Research

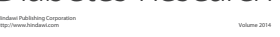

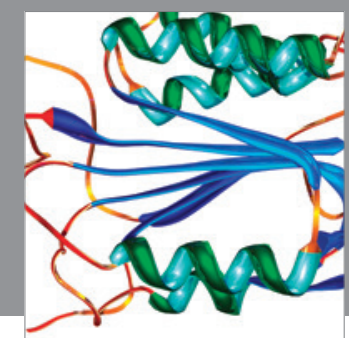

Disease Markers
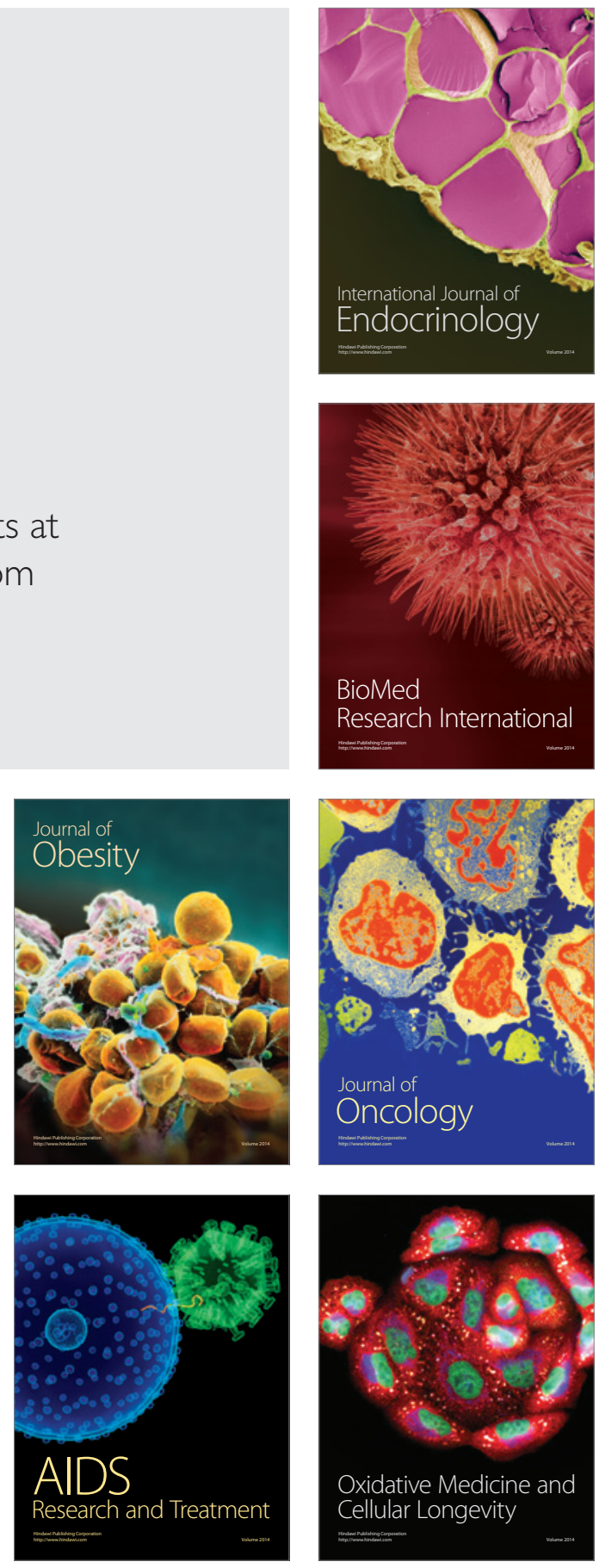